Foro Interno. Anuario de Teoría Política

ISSN: 1578-4576

http://dx.doi.org/10.5209/rev_FOIN.2015.v16.53890

\title{
Por una repolitización de los derechos humanos: Reflexiones en torno al artículo 29.1
}

\section{Edgar Straehle ${ }^{1}$}

Recibido: 2 de marzo de 2015 / Aceptado: 4 de mayo de 2015

Resumen. Este escrito reivindica el poco recordado artículo 29.1 de la Declaración Universal de los Derechos Humanos ante todo por dos razones: primero, porque reivindica el deber del individuo hacia la comunidad, tan importante para el cumplimiento real de los mismos derechos; segundo, porque este cumplimiento conduce además a un cuestionamiento constructivo sobre el resto de derechos de la Declaración y podría ser un fundamento para una ulterior revisión y regeneración. El artículo 29.1 interpela al individuo a la acción y lo invita a convertirse en un ciudadano en un sentido pleno, intentando superar cierta retórica de los derechos humanos, muchas veces instrumental y perjudicial, otras un factor de despolitización.

Palabras clave: Declaración universal de los derechos humanos; artículo 29.1; comunidad; deber; derechos humanos.

\section{[en] In Favour of a Repoliticisation of Human Rights: Reflections on Article 29.1}

Abstract. This contribution revisits the importance of article 29.1 of the Universal Declaration of Human Rights for two reasons: first, because individuals have a duty to the community, which this author holds as essential in order for their rights to be maintained; and secondly, because the achievement of this task promotes a critical and constructive questioning of other rights. The interpretation of article 29.1 offered here seeks to go beyond the human rights rhetoric, which can be empty, negative or may even become a strategy for depoliticisation.

Keywords: Universal Declaration of Human Rights; article 29.1; community; duty; human rights.

Cómo citar: Edgar Straehle, "Por una repolitización de los derechos humanos: Reflexiones en torno al artículo 29.1": Foro Interno. Anuario de Teoría Política, vol. 16 (2016), pp. 67-80.

\section{Introducción}

La Declaración Universal de los Derechos Humanos (DUDH) ha obtenido con el paso del tiempo una enorme y merecida relevancia. Sin lugar a dudas se ha convertido en un documento imprescindible desde el que comprender y enfocar la política actual. Lo que no ha logrado, empero, ha sido sustraerse de numerosas críticas, muchas de ellas pertinentes, que ponen en entredicho tanto su alcance como su fundamentación. Su amplia difusión, o su casi omnipresencia en la política exterior actual, ha generado

1 Universitat de Barcelona (España).
E-mail: edgarstraehle@gmail.com 
reacciones dispares que se han ido repitiendo de forma continua, concentrándose un buen número de ellas en los componentes culturales que intrínsecamente transmitían o en su alarmante falta de incidencia positiva en el mundo real ${ }^{2}$.

En este sentido, es conocida la crítica de que los derechos humanos constituyen la institución o la consagración de los derechos del individuo egoísta (así lo afirmó ya Karl Marx) y que, de alguna manera, repercuten negativamente en la misma humanidad a la que en principio se tenía intención de proteger. Una política de los derechos implicaría, desde esta difundida interpretación, la defensa de un individualismo altamente compatible y voluntaria o involuntariamente cómplice con las versiones menos amables del capitalismo. Los derechos santificarían unos mínimos tan reducidos y tan fácilmente resignificables que a la postre no evitarían su compatibilidad con formas de gobierno que, como en el caso de Sheldon S. Wolin (1922-2015), han sido identificadas con lo que ha denominado un totalitarismo invertido ${ }^{3}$. Los derechos humanos no serían más que una suerte de papel mojado o, peor todavía, un documento que llegaría al extremo de legitimar unas prácticas de gobierno diametralmente opuestas al espíritu que habría impulsado a la $\mathrm{DUDH}^{4}$.

Por su parte, Raymond Geuss, partiendo de la defensa de un modelo político como la democracia creativa del pensador pragmatista John Dewey (1859-1952) ${ }^{5}$, ha realizado una dura crítica que extiende a toda doctrina de los derechos y que queda resumida en el siguiente pasaje:

El discurso de los derechos es un modo de intentar inmovilizar la sociedad, de congelarla en una versión idealizada de su forma presente; no, por supuesto, de su forma presente real, dado que incluso los derechos reconocidos raramente se ponen en práctica de manera plena en ninguna sociedad ni en ningún momento. Es una tentativa de asegurar que la mano fantasmal del presente sea capaz de estrangular el futuro ${ }^{6}$.

Sin embargo, como proponemos en este escrito, también es posible plantear una lectura bien diferente de los derechos, una lectura que trate de descubrir un componente productivo y creativo en su seno. Y que por ende sea compatible con la democracia creativa de Dewey. Esta interpretación descansaría en la reivindicación de un artículo de la DUDH que para muchos es residual o secundario, que suele ser dejado de lado o que al menos no se halla ni mucho menos entre los más citados. No se tiene el propósito de salvar la DUDH de sus múltiples contradicciones,

2 No deja de ser desalentador en este sentido que Jeane Kirkpatrick, la embajadora de Estados Unidos en las Naciones Unidas durante el gobierno de Ronald Reagan, proclamase abiertamente que los derechos económicos, sociales y culturales expresados por la DUDH no eran a la hora de la verdad más que algo equivalente a una carta a Papá Noel. Noam Chomsky, Actos de agresión, Crítica, Barcelona, 2004, p. 96.

3 Sheldon S. Wolin, Democracia S.A., Katz, Madrid, 2008, passim.

4 Ver por ejemplo Jean Bricmont, Imperialismo humanitario: El uso de los derechos humanos para vender la guerra, El viejo topo, Barcelona, 2005; o Danilo Zolo, Terrorismo humanitario: De la Guerra del Golfo a la carnicería de Gaza, Edicions Bellaterra, Bellaterra, 2011.

5 John Dewey, "Democracia creativa", en Liberalismo y acción social y otros ensayos, Edicions Alfons el Magnànim, Valencia, 1996.

6 "Rights-discourse is a way of trying to immobilise society, to freeze it in an idealised version of its present form; not, of course, in its present real form, given that even recognised rights are rarely ever fully implemented in any society at any time. It is an attempt to ensure that the ghostly hand of the present is able to throttle the future". Raymond Geuss, History and Illusion in Politics, Cambridge University Press, Cambridge, 2001, p. 154 (Historia e ilusión en la política, Tusquets, Barcelona, 2004, p. 233). 
ambivalencias o limitaciones internas ni tampoco del uso o, mejor dicho, frecuente abuso instrumental que se ha hecho de esta declaración, algo a fin de cuentas inevitable. Más bien se trata de buscar una alternativa interna a la actual retórica de los derechos humanos que, por culpa de esgrimirlos estratégicamente como un arma política, no deja de frustrar o inhibir el potencial político, democrático y quién sabe si emancipador que podrían tener. Esta alternativa se enfrentaría asimismo a cualquier consideración reificadora o sacralizadora de la DUDH al propugnar un elemento autorreflexivo, dinámico y disruptivo en el seno de la comprensión de los mismos derechos que contenga la capacidad de responder a las críticas mencionadas $\mathrm{u}$ otras que pudieran presentarse en el futuro, incluyendo obviamente las que provienen de las culturas no occidentales; de responderlas no mediante palabras o declaraciones de buena voluntad, sino a través de una renovación o una regeneración internas con el fin de no caer en un inmovilismo de los derechos, y de que no se sigan afirmando sin ponerlos en cuestión unos contenidos de hace más de medio siglo como si fueran eternos, transhistóricos o transculturales. En otras palabras, se trataría de abrir la DUDH a los vaivenes de la historia y de la sociedad, y a las luchas que se desenvuelven en su seno, por lo que se criticarían los planteamientos políticos que hicieran de la DUDH una suerte de fundamento absoluto, inconcuso y monolítico de la política, lo que desembocaría en el riesgo de caer en un subordinacionismo acrítico y a fin de cuentas antipolítico.

Esta alternativa pasa por hacer una reivindicación y reconsideración del artículo 29.1, para nosotros cardinal pero sintomáticamente el penúltimo de la DUDH. Este artículo afirma de manera concisa que "toda persona tiene deberes respecto a la comunidad puesto que sólo en ella puede desarrollar libre y plenamente su personalidad" ". Lo primero que llama la atención radica en que nos encontramos con el único artículo en el que no se cita la palabra "derecho", pues más que un derecho nos encontramos en efecto ante un deber, lo que no deja de ser un motivo de controversia en nuestros días ${ }^{8}$. Por consiguiente, este artículo parece remitir a una tradición del derecho que no lo concibe de manera subjetiva sino objetiva y que tendría en la figura del jurista Samuel Pufendorf (1632-1694) a uno de sus representantes más significativos.

Este pensador del siglo diecisiete defendió vigorosamente en aquel entonces los derechos naturales del hombre, aunque subrayando asimismo la necesidad de establecer junto a ellos unos deberes fundamentales. Entre estos sobresalen por su importancia la creencia y el conocimiento de Dios, la de rendirle culto, la de conocerse a sí mismo o conocer nuestra propia naturaleza y desarrollarla, la de someter las pasiones a la razón, la de buscar la estimación y el honor o la de reconocer nuestra dependencia hacia Dios y hacia nuestros semejantes ${ }^{9}$. Muchos de estos deberes, que Pufendorf consideraba universales, no tendrían ningún sentido para una sociedad como la contemporánea, sobre todo los más propiamente religiosos. Sin embargo, lo

7 En todo momento se va a seguir la traducción oficial de la DUDH, que se puede encontrar en la página web oficial de las Naciones Unidas: http://www.un.org/es/documents/udhr/.

8 Conocida es en este contexto la tesis de Gilles Lipovetsky, quien ha expuesto la opinión de que nos encontramos en una sociedad posmoralista y del posdeber, donde se ha producido la delicuescencia de los valores tradicionales y tan solo se aceptan las normas indoloras. Gilles Lipovetsky, El crepúsculo del deber: La ética indolora de los nuevos tiempos democráticos, Anagrama, Barcelona, 1994, passim.

9 Ver Samuel Pufendorf, On the Duty of Man and Citizen according to the Natural Law, Cambridge University Press, Cambridge, 1991. 
que a nuestro juicio resulta remarcable, y es un aspecto que va a ser retomado más adelante, estriba en el hecho de que el jurista alemán destacó, en tanto que deber, la aprehensión de la propia naturaleza así como reconocer la dependencia que cada uno tiene hacia el prójimo.

Como es obvio, el artículo 29.1 no estipula unos contenidos tan concretos como los señalados por Pufendorf. En la DUDH no se fija en modo alguno un deber determinado a seguir. El enunciado es tan escueto, tan general, que puede ser soslayado y dejado de lado, como efectivamente así ha sucedido. A decir verdad, es normal que no haya suscitado un interés especial. Y la misma noción de "deber" a la que alude recibe una atención que podríamos catalogar de marginal a lo largo de la DUDH. De hecho, solamente en el artículo 29.1 aparece como sustantivo (duty). En otras tres ocasiones, de acuerdo con la traducción oficial al español, que es la que aquí nos interesa, se conjuga el verbo "deber": en un caso, en el artículo 1, se indica que los seres humanos deben, o más bien deberían (should), comportarse fraternalmente los unos con los otros, una exhortación a la fraternidad que, como se sabe, en innumerables casos no ha sido seguida ni siquiera por la misma Organización de las Naciones Unidas; en el preámbulo, en una formulación ambigua, se indica que los pueblos y naciones deben - y curiosamente se recurre a shall en la versión en inglés - esforzarse por promover el respeto, el cumplimiento y la aplicación de los derechos, lo que a la hora de la verdad no acarrea la asunción de ninguna obligación en particular; y, finalmente, en el artículo 26, se indica que la educación debe (shall) ser gratuita, cuanto menos en lo que se refiere a la elemental y a la fundamental.

Así pues, el término "deber" comparece en total en cuatro ocasiones ${ }^{10}$ : dos veces, conjugadas, como un deber del Estado hacia sus ciudadanos; otras dos veces, una no conjugada, la que aquí nos interesa, como deberes del ciudadano hacia los otros ciudadanos, aunque por su exposición aparecen como sumamente vagos y a la hora de la verdad no han derivado en el cumplimiento de ninguna obligación específica en la existencia real de las personas. Ciertamente hay otros pasajes que hacen referencia de manera indirecta a otros deberes, pero en ningún otro momento son encomendados al individuo, al sujeto de los derechos. De hecho, el mismo artículo 29.1 podría no haber existido. Como comentó en una anécdota muy ilustrativa René Cassin (18871976), considerado habitualmente como el principal autor de la DUDH, Eleanor Roosevelt (1884-1962) no quería incluirlo porque consideraba que dentro de una democracia liberal no había ni debía haber deberes u obligaciones ${ }^{11}$.

\section{El artículo 29.1 como garante de los derechos}

En el artículo 29.1 no se defiende un derecho pero debido a la inconcreción tampoco se puede decir que se enuncie propiamente un deber. A decir verdad, se podría argüir que lo que a fin de cuentas se expone es más bien una suerte de derecho de los demás que se le expresa a uno como la contracción indirecta de un deber. Este deber no sería en realidad más que un derecho camuflado o enmascarado, el derecho que

10 En la versión original el verbo "shall" sale hasta en 27 ocasiones, pero la mayoría de ellas en tanto que "shall be", donde la noción de deber se difumina.

11 René Cassin, "De la place faite aux devoirs de l'individu dans la déclaration universelle des droits de l'homme", en Problèmes des droits de l'homme et de l'unification européenne. Mélanges offerts à Polys Modinos, A. Pedone, Paris, 1968, p. 481. 
poseen la suma de otros, o la comunidad evocada, respecto de las personas que les rodean. Estas comparten un espacio común que, para serlo verdaderamente y tener la posibilidad de desarrollar libre y plenamente su personalidad, tal como el artículo 29.1 expresa, requiere una serie de intervenciones o actuaciones por parte de las personas que lo ocupan. El espacio común, allí donde se desenvuelve y se despliega la comunidad, precisa de su cultivo y de la participación para ser auténticamente común, para ser real y efectivamente el espacio de todos. Y la misma DUDH debería velar asimismo porque se diese esta participación en su seno para evitar que pudiera convertirse en un discurso obsoleto, extraño o superfluo, algo anacrónico o externo a los ciudadanos a los que pretende proteger.

Por eso, como se ha comentado más arriba, es el derecho del prójimo a recibir la acción del otro el que solicita el empeño o el esfuerzo comprometido de los demás, guiados a ser posible, si bien no de manera imprescindible, por algo semejante a la fraternidad evocada en el artículo 1. Y así se postula, de manera subrepticia y quizá involuntaria, un amago de libertad positiva que sobrepasa los muros de una concepción sociopolítica que nosotros llamamos del noli me tangere y que se encuentra plasmada ejemplarmente en las versiones más restrictivas de la libertad negativa o en las preocupaciones mencionadas en el artículo 12 de la DUDH ${ }^{12}$.

Como ha sido denunciado en distintas ocasiones, uno de los grandes peligros inherentes a los derechos consiste en que se abusa de una retórica que contribuye al encastillamiento del individuo en su privacidad y, de paso, a la indiferencia, o cuanto menos ausencia de juicio u opinión, por la vida de los demás, especialmente de esos otros oprimidos o desgraciados a quienes uno prefiere no mirar. Se ha afirmado en este sentido que el liberalismo, a la vez que valora de palabra la fraternidad, ha colaborado en el eclipse de esta, tal y como Antoni Domènech ha expuesto con brillantez en El eclipse de la fraternidad ${ }^{13}$.

Con el paso del tiempo, esta tendencia ha consagrado los quehaceres privados, ha debilitado los vínculos con el llamado prójimo y ha acabado por desterrar (o desahuciar) a los ciudadanos de la esfera pública. La política, en un atentado contra el significado original de esta palabra, se ha encerrado en numerosas ocasiones en el procedimentalismo, de entrada o en teoría bastante respetuoso con los derechos del individuo, a la vez que se ha procurado mantener alejado a este de las decisiones políticas. Si antes el ciudadano griego era aquel que, por ley, no debía estar ocupado en negocios particulares, ahora sucede algo diametralmente opuesto y se fomenta sin cesar la propagación de la conducta del idiotes tan vituperado en la antigüedad.

La crisis actual de la política tiene mucho que ver con la cristalización de este proceso histórico. Este exceso de atención hacia la libertad negativa también ha acabado por suponer un menosprecio creciente o un olvido de la libertad positiva, sin la cual no se puede garantizar aquella. Como se constata hoy en día, un individualismo excesivo semejante puede ser altamente perjudicial para los propios individuos, dado que entorpece la acción política de los ciudadanos y, en consecuencia, dificulta el cultivo, la emergencia y la consolidación de grupos o plataformas que, como es el caso de la sociedad civil, tengan la capacidad de oponerse en público a las decisiones

12 "Nadie será objeto de injerencias arbitrarias en su vida privada, su familia, su domicilio o su correspondencia, ni de ataques a su honra o a su reputación. Toda persona tiene derecho a la protección de la ley contra tales injerencias o ataques". El subrayado es nuestro.

13 Antoni Domènech, El eclipse de la fraternidad: Una revisión republicana de la tradición socialista, Crítica, Barcelona, 2005, passim. 
arbitrarias del Estado. Por eso, no debe extrañar que incluso uno de los pensadores liberales por antonomasia como Benjamin Constant (1767-1830) tratase en su momento de conciliar, en la medida de lo posible, lo que denominó la libertad de los modernos con la libertad de los antiguos ${ }^{14}$. John Rawls, en cambio, ha insistido en la posibilidad de que un régimen no democrático puede ser perfectamente compatible con uno que respete los derechos, como demostraría con el ejemplo ficticio de Kazanistán ${ }^{15}$. La cuestión consiste en saber cuánto tiempo se sostendría una situación parecida sin la presencia de una persistente lucha ciudadana que pugnase por la salvaguarda de esos derechos.

Sin libertad positiva, la negativa está constantemente en riesgo de ser ignorada o cuanto menos recortada, mutilada. Por esta razón, una defensa del artículo 29.1 adquiere en este contexto su relevancia, toda vez que sirve de soporte a los otros derechos y, en realidad, su reiterado y efectivo seguimiento es el que los hace plenamente posibles. La pensadora Martha Nussbaum ha escrito que los derechos fundamentales no son más que palabras hasta que la acción del Estado las convierte en reales ${ }^{16}$, aunque, como la historia se ha encargado de confirmar, es necesario que haya una ciudadanía activa que tenga la capacidad de alzarse y oponerse al gobierno para que se sigan respetando. Es gracias a que ciertas personas o colectivos sienten unos deberes o una responsabilidad hacia la comunidad que la DUDH puede hacerse cumplir y que la democracia puede tener ciertos visos de ser real y efectiva. En cambio, un gobierno que únicamente debe respetar los derechos individuales y que desatiende, o siembra de trabas, la labor política y pública de sus ciudadanos, está condenado a viciarse y a la larga acabará por vulnerarlos o derogarlos. Es necesario que exista una actividad ciudadana poderosa que refuerce el rol crítico y supervise la aplicación de los derechos. Toda política requiere la actuación de elementos contrapolíticos que no toleren ese potencial y frecuente descarriamiento.

Como se ha afirmado en múltiples ocasiones, el precio de la libertad es la vigilancia eterna, y debe tratarse de una vigilancia activa, plasmada en hechos para no desembocar en una democracia de ciudadanos pasivos o meros espectadores. Esto coincide incluso con uno de los ideales de Anthony Giddens, uno que ocupa un lugar preeminente entre sus propuestas políticas de la tercera vía, quien ha sostenido en múltiples ocasiones que no debe haber derechos sin responsabilidades ${ }^{17}$. Eso debe ser así, añadimos aquí, porque los derechos simplemente afirmados en textos como las constituciones de un Estado no son ni pueden ser en sí mismos performativos. No se puede seguir actuando sobre la base de lo que se ha llamado un legalismo mágico: es decir, aceptar como válidos y plenamente reales lo que aseveran los enunciados de tratados, convenciones, leyes o constituciones sin tener en cuenta que de facto se contradice sin cesar lo que en ellos se afirma ${ }^{18}$. Como se sabe, a la hora de la verdad la aceptación de la DUDH por los distintos países no ha significado su fiel cumplimiento sino que en muchos casos ha desembocado precisamente en

14 Benjamin Constant, Sobre el espiritu de conquista; Sobre la libertad en los antiguos y en los modernos, Tecnos, Madrid, 2002, p. 91.

15 John Rawls, El derecho de gentes; y una revisión de la idea de razón pública, Paidós, Barcelona, 2001, passim.

16 Martha Nussbaum, Crear capacidades: Propuesta para el desarrollo humano, Paidós, Barcelona, 2012 , p. 87.

17 Ver por ejemplo Anthony Giddens, La tercera vía: La transformación de la socialdemocracia, Taurus, Madrid, 1999, passim.

18 Véase por ejemplo Stanley Cohen, States of Denial: Knowing about Atrocities and Suffering, Polity Press, Cambridge, 2001, passim. 
todo lo contrario, gracias en parte al reconocimiento o incluso respaldo internacional que con dicho gesto se obtenía. También ha conducido a que dichos crímenes no sean condenados, contribuyendo de este modo a la propagación de injusticias que finalmente quedan impunes o que con frecuencia son deliberadamente ignorados por los medios de comunicación. La redacción de una constitución con rasgos liberales o democráticos no ha consistido en muchas ocasiones más que en la excusa con la que acallar las críticas de los organismos internacionales, a la vez que se podía perpetrar con descaro una política interior absolutamente contraria a lo ahí sostenido.

Por eso, aquí consideramos que el artículo 29.1 estriba, al fin y al cabo, en una manera de completar y asegurar que se observe lo que la misma DUDH expone en su Preámbulo, donde los derechos son descritos como

El ideal común por el que todos los pueblos y naciones deben esforzarse, a fin de que tanto los individuos como las instituciones, inspirándose constantemente en ella, promuevan, mediante la enseñanza y la educación, el respeto a estos derechos y estas libertades, y aseguren, por medidas progresivas de carácter nacional e internacional, su reconocimiento y aplicación universales y efectivos, tanto entre los pueblos de los Estados Miembros como entre los de los territorios colocados bajo su jurisdicción ${ }^{19}$.

En este preámbulo se expone un ideal común que no debe ser únicamente defendido, y gestionado, por los Estados. La aplicación de los derechos concierne a toda la población, ya que en caso contrario nadie puede garantizar que haya alguien o alguna institución que vaya a hacerlos respetar. Con esto no se afirma nada que no se conozca, puesto que el Estado es colocado en la misma DUDH como el garante pero, asimismo y de manera simultánea, como el principal sospechoso a la hora de respetar y hacer respetar los derechos. En este contexto, Christoph Menke y Arnd Pollmann han comentado acertadamente, en lo que han bautizado como la primera aporía de los derechos humanos, que:

El Estado, cuyos medios de poder son los únicos adecuados para hacer realidad los derechos naturales de los hombres en la sociedad, se ha evidenciado a la vez como la amenaza principal para los derechos humanos ${ }^{20}$.

Así pues, los derechos humanos parecen encontrarse ante una difícil tesitura. Su cumplimiento depende de la colaboración y el compromiso de una entidad que también se puede presentar y se ha presentado en sucesivas ocasiones a lo largo de la historia como su enemigo. Es esta inevitable ambivalencia del Estado la que concita la presencia indispensable de un actor distinto, si bien eso es algo que en realidad podemos extraer de la misma DUDH. Curiosamente, quizá de manera profética, el artículo 29.1 señala, pese a que ciertamente en el primer borrador no constaba

El subrayado es nuestro.

20 Christoph Menke y Arnd Pollmann, Filosofia de los derechos humanos, Herder, Barcelona, 2010, pp. 22-23. 
en modo alguno así $i^{21}$, que los deberes no son hacia el Estado sino que lo son hacia la comunidad. De este modo se apunta al protagonismo activo de los ciudadanos y también se trasciende la imprecisa fraternidad que aparece en el artículo 1, puesto que de este modo no se trataría del otro concebido como un ser abstracto o como el conjunto de todas las personas particulares, una versión actualizada de la célebre sentencia de Terencio (c. 194-159 a. C.) "soy hombre, nada de lo humano me es ajeno" (Homo sum, humani nihil a me alienum puto), sino como un colectivo concreto o determinado en el que esa persona estaría insertada.

Hay que precisar que por comunidad, un término ciertamente muy equívoco y a menudo empleado de manera instrumental, no nos referimos a una suerte de entidad supraindividual que reifica y falsea las relaciones que se dan continuamente entre las personas y las confunde con los intereses propios del Estado. Por lo tanto, no consiste tampoco en un dúctil significante que pueda servir para la edificación de una idea como la de nación, de pueblo o de nada semejante. La comunidad debe ser distinguida de estas abstracciones comunitaristas que no hacen más que reemplazar lo común, aquello que realizan todos sus integrantes a partir de su interacción e influencia mutuas, por un trasunto de lo individual aquí elevado a un nivel colectivo; es decir, por una idea concreta como la de nación (y todo el discurso identitario que eso trae consigo) que en el mejor de los casos guía y da significado a las acciones de las personas individuales o que, en un análisis más pesimista, desemboca más bien en la imposición de unas ideas e incluso de pautas de conducta específicas.

La comunidad, tal como han tematizado Jean-Luc Nancy ${ }^{22}$ y Roberto Esposito ${ }^{23}$, no coincide con las teorías del comunitarismo, pues sendos autores anteponen la importancia de la relación respecto al contenido que se vehicula en esta. La comunidad no significa entonces la asunción y el seguimiento de una serie de afirmaciones, en ocasiones bastante falsas o incluso inventadas recientemente de manera semejante a lo que Eric Hobsbawm (1917-2012) ha denominado "la invención de la tradición"24, sino un trato cotidiano con los otros que no desemboca ni tiene por qué desembocar en ninguna identidad o hipóstasis colectiva. Uno no se somete a unos enunciados homogéneos sino que, según esta concepción, la interacción continuada entre cada uno de sus integrantes deriva en que la defensa de la comunidad coincida justamente con la reivindicación de la diferencia y de la singularidad de cada uno, teniendo en cuenta que esta se transforma sin cesar gracias a la intervención ajena.

Entonces, aquello que importa ante todo y que hay que cuidar es el entre, el espacio que media entre los individuos y que debe ser ocupado por ellos en tanto que

21 No está de más comentar que el primer borrador fue realizado por John Humphrey, quien escribió que el individuo tenía deberes en relación al Estado y a las Naciones Unidas, lo que hubiera sido un enunciado bastante peligroso y más fácil de ser utilizado instrumentalmente. Ver Johannes Morsink, The Universal Declaration of Human Rights: Origins, Drafting and Intent, University of Pennsylvania Press, Philadelphia, 1999, p. 241. Al final, el rol predominante de las Naciones Unidas quedó de todos modos plasmado en el artículo 29.3 (que afirma que "estos derechos y libertades no podrán en ningún caso ser ejercidos en oposición a los propósitos y principios de las Naciones Unidas"), lo que a la luz de su comportamiento en las últimas décadas resulta una aseveración cuanto menos muy objetable. Este artículo 29.3 podría ser visto asimismo como un pretexto para bloquear numerosas iniciativas políticas legítimas e incluso necesarias.

22 Jean-Luc Nancy, La comunidad desobrada, Arena Libros, Madrid, 2001, passim.

23 Roberto Esposito, Communitas, Amorrortu, Madrid, 2005, passim.

24 Eric Hobsbawm, "Introducción: la invención de la tradición", en Eric Hobsbawm y Terence Ranger, $L a$ invención de la tradición, Crítica, Barcelona, 2002. 
quieran ser verdaderos ciudadanos ${ }^{25}$, un espacio que posibilita su enriquecimiento y transformación recíprocos y que asimismo impide su sumisión o sojuzgamiento a cualquier constructo ideológico. El entre no vendría determinado de antemano por ningún tipo de contenido definido. Sería, por el contrario, un espacio desprovisto de soberanía, sin la presencia de un poder absoluto que se arrogue el monopolio de la dimensión política de la comunidad. Por eso mismo, existe solamente en la medida en que hay un conjunto plural de personas que se mueven en su seno y que respetan y cultivan esta pluralidad ${ }^{26}$.

La comunidad, en conclusión, aparece desde esta perspectiva como la que prioriza el rol desempeñado por los otros con quienes uno se relaciona, porque en virtud de ellos uno no queda enrejado en los límites de su identidad y tiene la oportunidad de abrirse a una constelación de diferencias desde las que uno se constituye y reconstituye sin cesar. El otro, de este modo, es una invitación a que uno salga de sí mismo, sobrepase las fronteras que inhiben su desarrollo y valore este comercio social como la auténtica ley de la comunidad. Recordando asimismo, tal y como Hannah Arendt subrayó, que la ley (lex) para los romanos, aquello que Montesquieu tradujo de manera inteligente como rapport (relación), entroncaba con el verbo ligare y no era más que una alianza que enlazaba a dos pueblos distintos y enfrentados previamente en un destino o proyecto común ${ }^{27}$.

\section{EI artículo 29.1 como motor de los derechos (o los derechos contra los derechos)}

Esta concepción de la comunidad, aquí bosquejada mínimamente, se funda en una ruptura y disrupción continuas que coinciden, al menos hasta cierto punto, con el ideal de la democracia. Esta, como repetidamente ha indicado Claude Lefort ${ }^{28}$, se sustenta y se apuntala sobre la nada, sobre un espacio vacío que no puede ser ocupado o secuestrado definitivamente por ningún dogma, sobre un espacio que es intrínsecamente inapropiable por cualquiera de las partes. La democracia, al no tener ningún fundamento firme o absoluto, consistiría más bien en una actitud de cuestionamiento y de revisión constantes que, a nuestro juicio, también se corresponde en lo esencial con las implicaciones políticas que se extraen del artículo 29.1. Efectivamente, este postula los deberes que uno tiene respecto a la comunidad, aunque tales deberes por suerte no son especificados o enumerados. Esa inconcreción, ese deber sin un contenido concreto, es lo que le permite ser un fundamento tan legítimo como necesariamente precario, pues esos deberes pueden conducir a la larga a la desobediencia a la ley o quién sabe si frente a otros derechos afirmados en la DUDH. Desde esta interpretación, una ley o un derecho no son legítimos per se ni pueden ser considerados como absolutamente indudables o incondicionales. $\mathrm{La}$ legitimidad es necesariamente incompleta y provisoria, se halla dentro del marco de la historia y es siempre susceptible de ser puesta en duda, pues requiere un

\footnotetext{
25 No hay que olvidar en este contexto que Émile Benveniste ya indicó que en Roma la idea de ciudadano, civis, no significaba otra cosa que la de conciudadano. Émile Benveniste, Le vocabulaire des institutions indoeuropéennes. 1. Économie, parenté, société, Les éditions de Minuit, París, 1969, p. 337.

26 Para una profundización en la idea de espacio intermedio como el lugar propio de la política, Hannah Arendt, ¿Qué es la política?, Paidós, Barcelona, 1997, passim.

27 Ibid, pp. 121-122.

28 Claude Lefort, L'invention democratique, Fayard, Paris, 1981, passim.
} 
cuestionamiento constante, una especie de referéndum cotidiano que entronca con la precariedad referida.

Como es lógico, la pretensión de universalidad de los derechos es una universalidad discutida y con la que muchas culturas o colectivos no se identifican en absoluto, una universalidad imposible de satisfacer en verdad. No solamente es imposible por las inevitables aporías internas que se generan o por su posible inaplicabilidad. También lo es por culpa de lo que entraña ese mismo artículo 29.1, el cual puede ser visto como la fractura o hendidura necesaria que deben contener los derechos para aspirar a ser verdaderamente legítimos. La ausencia de universalidad no consiste, por lo tanto, en una crítica que invalide la DUDH; antes bien, debería ser aceptada como un rasgo natural a la esfera de los derechos. Los derechos no pueden ser aceptados o seguidos sin más y, de este modo, sacralizar de manera acrítica el contenido de esta o cualquier otra declaración. Los derechos no pueden librarse de su contingencia o de su historicidad y ser afirmados con una pretensión de universalidad, de modo que probablemente convendría entenderlos con mayor justicia como una respuesta coyuntural elaborada para hacer frente a una realidad cambiante. Los derechos, por eso, deben poseer asimismo la posibilidad de su cuestionamiento, corrección o derogación. La legitimidad de una ley, o de un derecho, se funda en una interacción y en un diálogo constantes con la sociedad o las sociedades a las que pretende dar cuenta, y esa interacción puede suponer la necesidad de plantear enmiendas, variaciones o añadidos.

En realidad, de una manera similar se tendió a ver los derechos hasta que triunfó lo que el historiador del derecho Paolo Grossi ha denominado la "mitología jurídica de la modernidad", por la cual se consumó la reducción del derecho a la ley y la sustitución paulatina de la legitimidad por la legalidad ${ }^{29}$. De este modo el Estado soberano se adueñó del poder jurídico, cuyas fuentes de legitimidad y de transformación antes descansaban en una pluralidad de instituciones y dependían asimismo del consensus fidelium. Entonces se impuso lo que Michel de Montaigne (1533-1592) bautizó como el fundamento místico de la autoridad, si bien hay que precisar que se trata ya de una autoridad que progresivamente se había alejado de su significado original y que se había aproximado a la idea de un poder cada vez más absoluto, arbitrario e implacable. La autoridad, como Thomas Hobbes (1588-1679) deja claro en el Leviatán, ya no es más que una herramienta del poder y se sustrae de su conexión con el "hacer crecer" que transmite el augere de su etimología y con la experiencia jurídica anterior, que para el pensador inglés era incompatible con la noción de soberanía y había coadyuvado en el estallido de la Revolución inglesa. En opinión de Hobbes, en una frase que mutatis mutandis no cesa de reproducirse hoy en día, toda ley por el simple hecho de ser ley era ya justa ${ }^{30}$, por lo que estaba completamente justificado aplicar el derecho de guerra contra el discrepante.

Como no puede ser de otra manera, también la DUDH es una respuesta mejor o peor a sus tiempos, una reacción necesaria frente a una catástrofe como la del nazismo y a los dramas que trajo consigo la Segunda Guerra Mundial. Sin embargo, no deja de ser imperfecta respecto de las problemáticas o miedos de nuestros días. La lectura que aquí se propone del artículo 29.1, por eso, no solamente plantea el

29 Paolo Grossi, Mitología jurídica de la modernidad, Trotta, Madrid, 2003, passim.

30 Thomas Hobbes, Leviatán, o, la materia, forma y poder de una república, eclesiástica y civil, Fondo de Cultura Económica, México D.F., 1980, p. 285. 
problema crucial que concierne a la correcta aplicación de los derechos gracias a la intervención de la ciudadanía. Y es que confiar en exceso y de manera acrítica en el Estado en tanto que fiel guardián de los derechos ha conducido históricamente a su incumplimiento y vulneración. Lo más importante, empero, yace en que dicho artículo puede servir asimismo para colocar a la misma DUDH, o a cualquier réplica que pudiera surgir en el futuro, en el epicentro del debate político, mientras que la retórica de los derechos, por el contrario, ha desembocado a menudo en una forma de despolitización y de limitación de la política. Menke y Pollmann insisten por eso en que los derechos humanos, más que morales, son políticos, por lo que politizar los derechos de manera inteligente, no sería más que hacerlos coherentes consigo $\operatorname{mismos}^{31}$.

Paradójicamente sería esta doble función, tanto la vigilante como la correctiva, tanto la policial o contrapolítica como la más propia o productivamente política, la que convertiría al artículo 29.1 en un legítimo fundamento último de los derechos: un fundamento relacional, sin contenido específico y que en el fondo no hace más que interpelar a los individuos a que formen parte activa de la comunidad. Como en la democracia, se precisa que haya un fundamento precario y desustancializado, que desconfíe de sí mismo y que por lo tanto no caiga en el dogmatismo. En verdad, como sucede con la desobediencia civil, la verdadera lealtad estriba precisamente en una lealtad crítica que muestre su preocupación por el devenir de los derechos y que evite practicar lo que Jürgen Habermas ha llamado el "legalismo autoritario" "32. El deber consistiría en la responsabilidad mencionada, una responsabilidad que al fin y al cabo no es más que la respuesta que cada uno debe dar personalmente, una suerte de contradon que no puede ser impuesto externamente.

La verdadera individualización de los derechos debería consistir en el derecho a la aportación de la propia diferencia que uno tiene y puede proporcionar u obsequiar a los demás. Esto coincide con Jean-François Lyotard (1924-1998) cuando el pensador francés afirmó: "asumamos que la capacidad de hablar a los otros es un derecho humano y tal vez el derecho humano fundamental" 33 . Más que un derecho se podría añadir que quizá sea más bien algo cercano a un deber. Los derechos no solamente tienen por qué circunscribirse a los que posee uno mismo sino también los que poseen los otros que nos rodean, lo que implica la necesidad de contraer determinados compromisos que no sean meramente negativos (como la no interferencia). $\mathrm{Y}$ eso exige un acercamiento o una comunicación con el otro que facilite una política del lazo (politique $d u$ lien) como la postulada por Nancy $^{34}$ o la política del don que a nuestro juicio se esconde en la obra magna del sociólogo Marcel Mauss (1872$1950)^{35}$. Se trataría de hablar al otro y de hacer que el otro nos hable; por supuesto, no con un otro cualquiera, lo que sería un ideal huero y demasiado naïf, demasiado poco ideal al fin y al cabo, sino alguien hasta cierto punto escogido que por diversas razones nos haya interpelado y alentado a dar ese paso. Uno trascendería sus propios límites

\footnotetext{
Menke y Pollmann, Filosofía de los derechos humanos, passim.

Jürgen Habermas, Ensayos políticos, Península, Barcelona, 2002, p. 64

"Let us take it that the capacity to speak to others is a human right, and perhaps the most fundamental human right". Jean-François Lyotard, "The Other's Rights", en Stephen Shute y Susan Hurley (eds.), On Human Rights: The Oxford Amnesty Lectures, 1993, Basic Books, New York, 1993, pp. 140-141.

34 Jean-Luc Nancy, El sentido del mundo, La Marca, Buenos Aires, 2003, passim.

35 Marcel Mauss, Ensayo sobre el don: Forma y función del intercambio en las sociedades arcaicas, Katz, Buenos Aires, Madrid, 2009, passim.
} 
para alcanzar al otro y saber así qué forma adoptaría ese deber, o qué contenidos debería poseer, aunque no sea este último quien lo marque o lo determine.

El artículo 29.1 aparece así como un híbrido entre lo propio y lo extraño, lo individual y lo ajeno. No se trata de un deber fijo, mucho menos uno proporcionado o dictado por el otro; es uno quien se lo impone o fija a sí mismo a partir de una escucha del otro; de atenderlo, también en el sentido que se desprende del idioma francés (el attendre que remite a la espera) o del inglés (el attend que se asocia a la asistencia a un lugar o acontecimiento). Uno traduce o interpreta lo que el interlocutor dice y actúa en consecuencia. Se precisa, por tanto, una comunicación, un encuentro real, si bien eso no deriva en el sometimiento ni tampoco en un acuerdo que disuelva el conflicto. Como es sabido, pese a que algunos acérrimos partidarios del diálogo parecen olvidarlo, todo encuentro puede degenerar perfectamente en un desencuentro e incluso en un encontronazo. Por eso, cuando uno sale de uno mismo para alcanzar al otro, no debe convertirse en él ni tampoco subordinarse o identificarse con lo que este desea. La comunidad necesita la presencia y la aportación de ambos, las distintas respuestas o preocupaciones de cada uno, incluyendo asimismo los malentendidos o conflictos que se pueden originar entre ellos, generando así un espacio común de la política y para la política.

En realidad, la respuesta a la escucha no consiste en la obediencia y con frecuencia puede llegar a plasmarse mucho mejor en lo contrario. El deber no es con el otro sino con la comunidad plural de otros que nos circundan. Hay un sinfín de posibilidades que se abren en torno a cada uno y el deber expuesto, en realidad, más que ser un acto de puro y abnegado altruismo, a la larga puede o tiende a repercutir positivamente en uno mismo. En ese indefinido deber al fin y al cabo inexigible (y que en realidad se mueve en una dimensión supererogatoria) hacia los demás se puede esconder asimismo un deber hacia uno mismo. Uno crece, aprende y mejora en virtud de la aportación de los otros en esta especie de ascesis de la sociabilidad que, ni mucho menos, implica el sacrificio de las parcelas de intimidad o de soledad que cada uno dispone o atesora legítimamente.

Es preciso reconocer antes de concluir que este artículo 29.1 no es más que un derecho o deber imposible, y no solamente por los componentes utópicos que comprensiblemente se le puedan achacar. Es imposible porque hablamos de un deber que en realidad, y de manera intrínseca, no tiene la capacidad de obligar ni es esto lo que persigue. Al fin y al cabo, ob-ligar no sería más que un modo erróneo y contraproducente de ligar a las personas. Por eso, se trata más de una exhortación, o incluso una incitación, que un deber. De ahí que se refugie justamente en la inconcreción y en la indefinición que cada uno de sus actores debe concretar o definir con su acción. Este es su punto fuerte (a nivel teórico) pero también su innegable punto débil (a nivel práctico). Eso le permite aparecer sin problema, sin generar demasiados conflictos o contradicciones, si bien redunda obviamente en la posibilidad de su no seguimiento. O también en la posibilidad de que ese seguimiento sea polémico y no sea reconocido como tal.

El artículo 29.1 no tiene la fuerza o la capacidad de obligar porque muchas veces, o quizá necesariamente, su cumplimiento es precisamente el rechazo a la obediencia, el cultivo de una suerte de autonomía o distancia crítica por parte de los integrantes de la comunidad. Indirectamente se prescribe una libertad que no solamente es positiva, puesto que llama a los ciudadanos a intervenir en la vida pública, sino que puede consistir en un acto desafiante que rete a los poderes establecidos o a las leyes 
aceptadas, o que derive en un llamamiento a la desobediencia civil.

El citado artículo 29.1 estimula la acción ciudadana, una acción que Arendt consideraba como una categoría fundamental de la política y que, por definición, se debía dar en el espacio intermedio así como en concierto con los demás, que estaba atravesada por la pluralidad y que se vinculaba a lo inesperado y a lo imprevisto ${ }^{36}$. Propiamente no se saben ni se pueden predecir las consecuencias de lo que significaría el cumplimiento del artículo 29.1. Ahí se muestra lo que para muchos sería su carácter de phármakon, tan necesario como peligroso, tan seductor como amenazador, tan revolucionario para unos como imprudente, irresponsable o insuficiente para otros.

Concluimos señalando que el fundamento de los derechos no solamente es un fundamento extraño e incluso negativo, por el hecho de tener la capacidad de cuestionar o despensar (según la expresión de Sousa Santos) ${ }^{37}$ los contenidos enunciados en el resto de artículos y exponerlos como contingentes, sino que se trata asimismo de un fundamento precario o en sí irrealizable, imposible de fijar, porque implica la complicidad enérgica de una ciudadanía que nadie puede asegurar $\mathrm{y}$, mucho menos, forzar. Únicamente consistiría en una interpelación que muchas veces, por desgracia, puede derivar en una sorda indiferencia. Que este derecho no pueda ser asegurado, que precise la acción o la contribución ciudadana, que se asemeje más a una supererogación que a un deber, es lo que delata su carácter incierto, inevitablemente dependiente de los avatares históricos de cada momento.

\section{Referencias bibliográficas}

Arendt, Hannah, ¿Qué es la política?, Paidós, Barcelona, 1997.

—, La condición humana, Paidós, Barcelona, 2005.

Benveniste, Émile, Le vocabulaire des institutions indo-européennes. 1. Économie, parenté, société, Les éditions de Minuit, Paris, 1969.

Bricmont, Jean, Imperialismo humanitario: El uso de los derechos humanos para vender la guerra, El viejo topo, Barcelona, 2005.

Cassin, René, "De la place faite aux devoirs de l'individu dans la déclaration universelle des droits de l'homme", en Problèmes des droits de l'homme et de l'unification européenne. Mélanges offerts à Polys Modinos, A. Pedone, Paris, 1968.

Chomsky, Noam, Actos de agresión, Crítica, Barcelona, 2004.

Cohen, Stanley, States of Denial: Knowing about Atrocities and Suffering, Polity Press, Cambridge, 2001.

Constant, Benjamin, Sobre el espíritu de conquista; sobre la libertad en los antiguos y en los modernos, Tecnos, Madrid, 2002.

De Sousa Santos, Boaventura, Crítica de la razón indolente: Contra el desperdicio de la experiencia, Desclée de Brouwer, Bilbao, 2003.

Dewey, John, "Democracia creativa", en Liberalismo y acción social y otros ensayos, Edicions Alfons el Magnànim, Valencia, 1996.

Domènech, Antoni, El eclipse de la fraternidad: Una revisión republicana de la tradición socialista, Crítica, Barcelona, 2005.

\footnotetext{
36 Hannah Arendt, La condición humana, Paidós, Barcelona, 2005, passim.

37 Boaventura de Sousa Santos, Crítica de la razón indolente: Contra el desperdicio de la experiencia, Desclée de Brouwer, Bilbao, 2003, passim.
} 
Esposito, Roberto, Communitas, Amorrortu, Madrid, 2005.

Giddens, Anthony, La tercera vía: La transformación de la socialdemocracia, Taurus, Madrid, 1999.

Geuss, Raymond, History and Illusion in Politics, Cambridge University Press, Cambridge, 2001. [Edición en castellano: Historia e ilusión en la política, Tusquets, Barcelona, 2004].

Grossi, Paolo, Mitología jurídica de la modernidad, Trotta, Madrid, 2003.

Habermas, Jürgen, Ensayos políticos, Península, Barcelona, 2002.

Hobbes, Thomas, Leviatán, o, la materia, forma y poder de una república, eclesiástica y civil, Fondo de Cultura Económica, México D.F., 1980.

Hobsbawm, Eric, "Introducción: la invención de la tradición”, en Eric Hobsbawm y Terence Ranger, La invención de la tradición, Crítica, Barcelona, 2002.

Lefort, Claude, L'invention democratique, Fayard, Paris, 1981.

Lipovetsky, Gilles, El crepúsculo del deber: La ética indolora de los nuevos tiempos democráticos, Anagrama, Barcelona, 1994.

Lyotard, Jean-François, “The Other's Rights”, en Stephen Shute y Susan Hurley (eds.), On Human Rights: The Oxford Amnesty Lectures, 1993, Basic Books, New York, 1993.

Mauss, Marcel, Ensayo sobre el don: Forma y función del intercambio en las sociedades arcaicas. Buenos Aires, Katz, Madrid, 2009.

Menke, Christoph y Pollmann, Arnd, Filosofía de los derechos humanos, Herder, Barcelona, 2010.

Morsink, Johannes, The Universal Declaration of Human Rights: Origins, Drafting and Intent, University of Pennsylvania Press, Philadelphia, 1999.

Nancy, Jean-Luc, La comunidad desobrada, Arena Libros, Madrid, 2001.

—, El sentido del mundo, La Marca, Buenos Aires, 2003.

Nussbaum, Martha, Crear capacidades: Propuesta para el desarrollo humano, Paidós, Barcelona, 2012.

Pufendorf, Samuel, On the Duty of Man and Citizen according to the Natural Law, Cambridge University Press, Cambridge, 1991.

Rawls, John, El derecho de gentes; y una revisión de la idea de razón pública, Paidós, Barcelona, 2001.

Wolin, Sheldon S., Democracia S.A., Katz, Madrid, 2008.

Zolo, Danilo, Terrorismo humanitario: De la Guerra del Golfo a la carnicería de Gaza, Edicions Bellaterra, Bellaterra, 2011. 